\title{
Senior Entrepreneurship in Lebanon: Determinants of Intentions
}

\author{
Boutros Dgheim ${ }^{1} \&$ Wadad Saad ${ }^{2}$ \\ ${ }^{1}$ Faculty of Economics and Business Administration, Lebanese University, Tripoli, Lebanon \\ ${ }^{2}$ Doctoral School of Law, Political, Administrative and Economic Sciences, Lebanese University, Sin el Fil, \\ Beirut, Lebanon \\ Correspondence: Wadad Saad, Doctoral School of Law, Political, Administrative and Economic Sciences, \\ Lebanese University, Sin el Fil, Beirut, Lebanon. Tel: 961-3-880-036. E-mail: wsaad@ul.edu.lb or \\ wsaad96@hotmail.com
}

Received: March 5, 2019

Accepted: April 16, 2019

Online Published: April 25, 2019

doi:10.5539/ijef.v11n6p45

URL: https://doi.org/10.5539/ijef.v11n6p45

\begin{abstract}
This study investigates the determinants of the senior-entrepreneurial intentions in Lebanon. It is based on the analysis of 50 comprehensive interviews with senior Lebanese entrepreneurs that were used to identify 21 preliminary determinants of senior-entrepreneurial intentions in Lebanon. In addition to this qualitative component, this study also draws on theories about determinants of intention to elaborate its first model. To test the validity of the first model, a questionnaire was distributed among Lebanese seniors. The answers of 1,142 respondents allowed us to elaborate a final model of the determinants of entrepreneurial intentions among seniors in Lebanon.
\end{abstract}

Keywords: Senior-entrepreneurship, entrepreneurial intentions, behavioral attitudes, structural equations

\section{Introduction}

Similarly to other countries in which life expectancy has risen, the elderly population is increasing in Lebanon. As a result, the general economic inactivity of this segment has increased the pressures on pension and social security systems since most of the elderly are often in good health and, therefore, potentially productive. Many policies exist that aim at improving the financial and social situation of the elderly, but these policies have put a heavy burden on the Lebanese economy, which already suffers from a huge amount of public debt in relation to the country's gross domestic product. Hence, there is clearly a need for alternative policies such as the promotion and stimulation of entrepreneurship among the elderly, an alternative that should be addressed by public policy makers.

Senior-entrepreneurship offers older workers a means to supplement their income and to avoid social disengagement. It allows them to return to work in order to cope with rising cost of living and other social problems. However, in Lebanon, only a handful of seniors have resorted to senior entrepreneurship, which is not widespread in the country due to legal, financial, cultural and contextual constraints. Thus, the Lebanese government should play a large role in promoting and fostering senior leadership as a means to engage seniors in the service of the country and its citizens.

However, it should be noted that entrepreneurship is a process that is intrinsically related to entrepreneurial intent, and that both cannot be tackled separately. Entrepreneurial intention is the state of mind that precedes the first action an individual takes in order to start a business and engage in the entrepreneurial process. It can be described as the personal will or initiative to create one's own business. Thus, supporting entrepreneurial intentions is of particular interest to economists and policy makers because business creation contributes to economic and social development.

Due to the impact of aging populations on the economy of many countries, senior entrepreneurship and entrepreneurial intentions have become the focus of various studies. In Lebanon, however, these studies are either limited or virtually neglected by researchers. As a result, this study aims at addressing this research gap that exists in Lebanon by investigating the entrepreneurship capacity of seniors, their intentions and their perspectives of creating new businesses.

Obviously, the results of such a study have both practical and theoretical implications. At the theoretical level, it can provide a basis for the development of future projects related to senior entrepreneurship and intent locally. At 
the practical level, it can offer the following contributions to the field: Provide a valuable insight into the position of Lebanese senior entrepreneurs by identifying the gaps in the entrepreneurship capacity of senior citizens in Lebanon and search for best practices, Make recommendations for promoting entrepreneurship among seniors in Lebanon, Determine the factors that explain the entrepreneurial intention among Lebanese seniors in order to assist policy makers in their task of promoting and supporting entrepreneurship among the elderly, and help seniors to improve the socio-economic situation in Lebanon.

This study is organized as follows: section two presents the literature review related to the research topic; section three explains the methodology used to address the research objectives; section four describes the data collection process and analysis; section five presents and discusses the results and main findings of the study; and the final section includes a conclusion and provides some recommendations.

\section{Literature Review}

The process of entrepreneurship requires a state of mind and a dynamic action by the individual entrepreneur that can be acquired through training, awareness of situations, and other accompanying measures (Boudabous, 2011). In actuality, entrepreneurs create new businesses by producing interests and services that cater to the needs of their communities and benefit society as whole. Entrepreneurship also creates good returns for different stakeholders and offers new job opportunities, thus helping to lower unemployment and to diversify the industrial sector. It is therefore clear that there exists a strong relationship between the start-up rate and economic growth (Zimmern \& Kalmykova, 2015).

Senior entrepreneurs are individuals who have started an entrepreneurial experience, i.e., the creation or takeover of a business, during the second part of their careers, more specifically at 50 and over (Bornard \& Abord de Chatillon, 2016). Since senior entrepreneurship offers potential socio-economic benefits to these individuals, one of the objectives of the policies that promote senior entrepreneurship should be to create a positive and stimulating environment that encourages older people with entrepreneurial ambitions to flourish. Thus, policy makers should carefully monitor the transition of seniors from relying on social assistance such as state pensions, to engaging in independent economic activities that bring added value to society (Halabisky, 2013).

Senior entrepreneurs possess assets that are valuable in business. They benefit from the accumulated human capital they gathered during their previous work experience (Botham \& Graves, 2009). It has been noted, for example, that an individual who has had managerial experience has a higher impact on productivity than one who has had experience as an industrial worker (Kautonen, Down, \& South, 2008). Furthermore, the social capital of seniors has more significant effects because they are expected to have larger networks of personal contacts that can facilitate the success of a new project (De Bruin \& Firkin, 2001). However, it must be noted that the reach of such networks declines with age and the relevance of a network depends on the former work experience of the individual (Botham \& Graves, 2009).

Regarding the accumulated financial capital, a senior individual may possess, this asset can also have a two-fold effect on his/her tendency to undertake a new business project. Whereas the positive impact of having financial capital clearly facilitates the start of a new project, senior individuals may also feel that they are no longer motivated to generate additional revenue (Singh \& DeNoble, 2003).

Moreover, it is assumed that the elements that characterize senior entrepreneurs at the individual level, as mentioned beforehand, also exist at the national-level. Therefore, national characteristics play an important role in determining the specific aspects and effects of senior entrepreneurship on a given economy. To begin with, government policies on bureaucracy and taxes, and the level of education (in terms of entrepreneurship) in countries that have low rates of senior entrepreneurship are different from those that have higher rates. Secondly, research and development (R\&D) spending seems to be a common feature of countries with higher senior entrepreneurial activities. Thirdly, funding and higher vocational education do not necessarily have a significant relationship with rates of senior entrepreneurship. Fourthly, and paradoxically, countries that have low rates of senior entrepreneurship have vibrant markets, which is not the case in other countries (Pilkova, Holienka, \& Rehak, 2014).

Senior-entrepreneurship and entrepreneurial intent are interrelated processes and, therefore, inseparable. The latter is the first act in the entrepreneurial process (Saleh, 2011) and encompasses the personal desire to create one's own business (Benredjem, 2009). The entrepreneurial intent is of particular interest to economists, researchers and policy makers since business creation contributes to economic and social development.

Hence, in order to study the entrepreneurial act it is necessary to first address the element that determines the beginning of the entrepreneurial process, that is, the intention. 
Entrepreneurial intention, in general, can be explained by two approaches: the individual specificities approach and the environmental approach (Bourguiba, 2007). According to the individual characteristics approach, entrepreneurial behavior can be predicted by identifying a set of personality traits and other psychological characteristics (Emin, 2004). The environmental approach, on the other hand, assumes that the will to create a business depends on the individual's cultural, social, familial, political and economic environment since a human being is seen as sociable by nature. In addition, it assumes that entrepreneurs who have an extensive social network and personal ties are better able to identify more opportunities (Bourguiba, 2007).

Several researchers have attempted to create models of entrepreneurial intent. Shapero and Sokol (1982), for example, developed the theory of entrepreneurial event. In their model, the authors identified three groups of factors that underlie the initiation of the entrepreneurial event: negative conditions (divorce, dismissal, dissatisfaction at work); positive changes (family, obtaining an inheritance, winning the lottery, discovering a new product, new know-how, or discovering a new market for an existing product, discovering a possibility of financing, etc.); and intermediate situations such as retirement. At the interface of these three groups, the authors identified two groups of intermediate variables: perceptions of desirability and perceptions of feasibility.

Bird (1988) considered intention an individual's will and assumed that the individual's personal profile, such as experience, personal characteristics and personal ability, in tandem with political, economic and social factors, such as government regulation can contribute to the formation of entrepreneurial intent.

Ajzen's (1991) Theory of Planned Behavior (TPB) postulates that an individual's behavior is best predicted by his/her intentions which, in turn, are predicted by attitudes about a specific act or behavior, the individual's perception of social norms, and his/her perception of their control over the behavior.

Krueger and Carsud (1993) were inspired by the work of Shapero and Sokol (1982) to develop a model that remained at the theoretical and hypothetic level without showing its empirical results. The goal of Krueger and Carsrud's investigation was to show that it is possible to apply a model widely used in social psychology in the field of entrepreneurship to predict a variety of behaviors. The intention is, therefore, the best predictor of entrepreneurial behavior (Krueger \& Carsrud, 1993).

The above-mentioned authors identify three essential factors, called exogenous influences, which antecede intention:

1) The individual perception of the attractiveness of the entrepreneurial behavior, which is assumed to depend on the likelihood of achieving the desired positive behavioral outcomes.

2) The perception of social norms which supposedly dependent on the perception of the social pressures that favor or inhibit the entrepreneurial behavior. Thus the availability of entrepreneurial models to the individual may act on his/her intention to undertake a new project.

3) The perception of the self-efficacy or feasibility of the behavior. The authors emphasize that this factor is a predictor of a multitude of behaviors. Since individuals choose behaviors they can control, the perception of the self-efficacy of the behavior is a useful tool to explain the creation of a business.

Krueger and Carsrud (1993) also added that exogenous factors (skills and abilities, personality traits, availability of resources, economic situation, etc.) indirectly influence the behavior in the form of perceptions, and act directly on the link that exists between intentions and behaviors.

In 2011, Maaloui, Bourguiba and Safraou conducted an exploratory study on senior entrepreneurship in which they proposed a conceptual model of entrepreneurial intent, which they believed existed among seniors. However, the contribution of their study is largely theoretical. By focusing on desirability and feasibility, the authors highlighted a number of factors that influence entrepreneurial intent. According to the interviews conducted in the study, the reasons most individuals opted for an entrepreneurial experience are the dismissal from a job, the fear of retirement, or the desire to leave a heritage to their offspring. However, it is also true that most senior entrepreneurs feel mature enough to create a solid structure that allow them to pass on the know-how they had developed with experience. Likewise, it appears that older entrepreneurs have, in most cases, a fairly solid expertise on the field in which they create companies. Thus, the authors state that "the variables: age, previous professional experiences, social networks influence the future senior entrepreneur in his perception of the feasibility of his project" (p. 12).

Moreover, the interviews conducted by the authors show that senior entrepreneurs are people who are particularly concerned about the future and interested in future projects, a proof that their involvement in the working life continues after retirement. However, in addition to economic matters, such as the economy and job experience, entrepreneurs over 50 also have family and personal obligations. 
Malaooui et al. (2011) explained that when a person is dismissed at age 50, he or she has difficulty finding work in a competitive job market and is compelled to create his or her own job. According to the authors, senior entrepreneurs in this situation must meet the needs of their children and maintain their previous life style. Thus, their conduct reflects the fact that financial needs are essential to drive people to undertake new ventures. By observing these various aspects, the authors inferred that "family status, career, perceived income, dependent children and the social role preceding retirement, influence the future senior entrepreneur in his perception of the desirability of the organization that he will create" (p. 12).

In their study, the researchers also identified a central element, namely, the desire of senior entrepreneurs to transmit something to future generations, such as family members or other members of their community. This desire can be materialized by transferring the property of a company to their family and descendants or by transferring knowledge to young employees or associates (know-how, experience, for example). Thus, in their study, Maalaoui and al. expanded the concept of "generativity" pioneered in the works of Erikson (1963, 1969, 1982). Generativity postulates that the entrepreneurial intention of seniors is stimulated by their desire to leave a few things to their descendants. However, the rate of such intention decreases at an advanced age because of the deterioration of health (Maalaoui, Bourguiba, \& Safraou, 2011).

In this study we will examine the adequacy of the models discussed above to address the situation of seniors in Lebanon, and attempt to create an approach that may effectively describe the central aspects of senior entrepreneurship in the country.

\section{Methodology}

This study attempts to explain the entrepreneurial intention among Lebanese seniors (dependent variable) by using several determinants of entrepreneurial intention (independent variables). These variables refer to subjective phenomena that are, nonetheless, objectively measured by reliable measurement scales, specifically a 5-point Likert scale ranging from "strongly disagree" to "strongly agree."

To do so, we conducted two types of investigation: a qualitative one that aimed at constructing a set of research hypotheses concerning senior entrepreneurship in Lebanon; and a quantitative study which was conducted to test these hypotheses by using a conceptual model. Structural Equations Modeling was utilized to statistically verify hypotheses and to validate the study's conceptual model in two stages: Exploratory Factor Analysis, and Confirmatory Factorial Analysis.

\section{Data Description}

As previously mentioned, this study consists of a qualitative and a quantitative analysis. The qualitative analysis was performed by using semi-directive interviews with senior entrepreneurship in Lebanon conducted in 2015. The senior interviewees were part of a group formed by former employees in the public and private sectors with small children, former single employees, former married employees without dependent children, and senior female entrepreneurs. We also identified four types of companies created by seniors: individual and/or small companies, limited liability companies, companies with low start-up, and home-based businesses.

According to Evrard, Pras, and Roux (2009), the purpose of semi-directive interviews is to explore in depth the field of research in order to reveal the richness of its content, depth, and diversity. The authors also assume that working with small sample sizes is sufficient since the purpose of semi-directive interviews is not constrained by any statistical representativeness. Much earlier, in 1967, Glaser and Strauss observed that any number of interviews was sufficient if new interviews did not generate new ideas in comparison with previous ones.

Based on the principle of theoretical saturation proposed by Glasser and Straus, we carried out our qualitative stud by using interviews conducted with 50 senior entrepreneurs in Lebanon. Our goal was to identify the factors that motivate the seniors who had started a new job at age 50 or older had about their working life. In doing so, we attempted to understand their behavior, record their impressions, and analyze their attitudes towards their work.

To conduct the interviews, we used a guide that included four pre-established questions, as well as a few questions about the profile of each interviewee. The pre-established questions addressed the pull and push factors. The questions designed to delineate individual profiles focused on the specific characteristics of each interviewee (age, level of education, previous experience, etc.).

This study's quantitative analysis was based on relevant theories and supported by the hypotheses extracted from the qualitative study. This approach was used to develop a conceptual model to investigate the determinants of the entrepreneurial intentions among seniors in Lebanon. Data to create this model were collected by distributing a questionnaire that was administered to seniors in different Lebanese regions. In order to measure 
the respondents" perceptions, 5-point Likert scale ranging from "strongly disagree" to "strongly agree" was used to measure the answers to the questionnaire. The respondents would then be evaluated according to a series of propositions about what he or she had been invited to express and their level of agreement or disagreement.

To do so, 1,200 questionnaires were distributed between May 2016 and September 2016. The total number of respondents who completed the questionnaire was 1,142 . The remaining 58 questionnaires handed in had been partially complete or had missing responses. However, many surveys are tainted by non-response, a phenomenon in which the persons in the selected sample do not provide the information requested. Thus, non-response can significantly alter the quality of survey results (Bethlehem, Cobben, \& Schouten, 2009). To address this limitation, the demographic, geographic and socio-economic characteristics of non-respondents were identified and compared with those of the respondents. It was noted that the characteristics of the non-respondents were similar to those of the respondents. As a result, it was possible to neglect the non-responses and protect the results from the risk of bias.

To administer the questionnaire, we used a face-to-face mode of data collection. Although this approach can reveal the disengagement and weariness of respondents (Menvielle, 2011), it offers a multitude of features, such as sample control, adaptability to the respondent, and flexibility in administering questions. However, a face-to-face survey is the most costly mode since it requires a large number of humans and a large amount of time. In spite of these hurdles, in our study the face-to-face surveys took place at the interviewees' home, at companies and public administration offices, and on the street.

In addition, this study utilized the random sampling method in the quantitative study, which, as noted by Feghali (2015), requires defining the data quality and obtaining an optimal sample.

The questionnaire also took into account the socio-demographic variables in order to highlight the profile of the respondents. The same variables were utilized to identify their entrepreneurial intentions. As for addressing their behavioral attitudes, the respondents were asked to assess factors, such as family and social environment that had an impact on their entrepreneurial motivation. The direct questions asked to the participants focused on whether they had a previous entrepreneurial idea, and on whether they had access to critical information about their projects.

Regarding subjective norms and factors that influenced the participants' desirability, the assessment of their savings and income adequacy reflects, respectively, their desire to ensure a higher level of financial security and their desire to increase returns. Similarly, the question about satisfaction with their current work reflects the respondents' interest in attaining job satisfaction. In turn, the respondents' aversion to social isolation and their willingness to help others reflect their desire to avoid social disengagement and to preserve their previous social role. In addition, the respondents' desire for self-fulfillment was measured by assessing their dreams and ambitions. Likewise, the respondents' desire for autonomy was measured by assessing their autonomy preference. The respondents' tolerance for risk-taking is reflected in their reactions to risk aversion. The willingness to leave an inheritance or other material benefit to their offspring was directly evaluated. The respondents directly assessed the availability of time and self-financing capacity, extensive work experience and effective social relationships, i.e., perceptions of behavioral control. Affiliation to associations, on the other hand, was measured by asking the respondents whether they were members of a municipality or an NGO.

\section{Results and Discussion}

This study shows two types of results, a qualitative one, that reflects the interviews, and the study's quantitative findings that are based on a conceptual model.

\subsection{Qualitative Results}

The results of the interviews conducted with 50 senior entrepreneurs in Lebanon, show that their entrepreneurial intentions were influenced by four groups of determinants.

\subsubsection{First Group of Determinants: Factors Associated with the Attitude Toward Behavior}

In this group we identified three elements. First, the existence of a more or less formalized idea. For some interviewees, the main reason that determined the entrepreneurial act was their previous possession of an idea. However, the country's laws did not allow them to start their own business, as it was, for example, the case of one public sector employee. In addition, some interviewees initiated their own business as soon as they returned to Lebanon from the countries to which they had emigrated since they had formed their entrepreneurial intent while living abroad.

Secondly, the availability of certain critical information to those individuals who had created their own business. 
Availability of information was a decisive factor for seniors to initiate their own venture. For some interviewees, the specific information available to them was the main reason for creating their own business. For one senior person, for example, his position had allowed him to access an important piece of information concerning a specific sector. Once he had gained that knowledge he decided to invest. Another entrepreneur who had been an employee at a Lebanese company specialized in commerce liked their business and chose to invest in the same area. Their experience shows that the availability of specific information is an important motivator for individuals to initiate a business.

Third, the positive evaluation of individuals regarding his or her past experience. Our qualitative study confirmed that a favorable self-assessment stimulates the interest of seniors in entrepreneurship, for example, due to the current civil war in Syria and the resulting migration of Syrians to Lebanon, a number of more or less wealthy families of migrants spend their money in the country and use various services during their stay in Lebanon. Consequently, one senior entrepreneur realized that the services would become essential and lucrative and decided to invest in the service sector.

Since these three elements related to entrepreneurial intentions were associated with behavioral attitudes, this study's first hypothesis is as follows:

(Hypothesis 1): Behavioral attitudes, reflected by the existence of a more or less formalized idea, available information and favorable assessment of the situation, significantly affect the intention of a senior to initiate a new business.

\subsubsection{Second Group of Determinants: The Variables Concerning Subjective Norms and Desirability}

The variables concerning subjective norms and desirability of senior-entrepreneurial intention in Lebanon includes the following elements.

First, the desire to improve financial performance and to ensure a higher level of financial security. It is clear that most entrepreneurs, including older workers, rely on entrepreneurship for financial reasons, mainly to generate additional income. The interviews showed that a number of senior entrepreneurs relied on an entrepreneurial activity to obtain additional returns necessary to ensure a better quality of life for their families. In their answer to the question, "Why did you decide to start a new business?" most interviewees said that they had started a new venture to increase their income. It is obvious that these interviewees were pressed to start a business for financial reasons. Moreover, according to our interviews, insufficient savings, low pensions, and the indemnity of end of their service pushed senior Lebanese to initiate a business. Some senior entrepreneurs decided to start a business because either they had not saved enough money for retirement or relied on an insufficient pension or severance pay.

In second place, the desire to avoid social disengagement and to preserve one's social role. Since retirement and unemployment are factors that can cause disengagement and separation from various social groups. For some seniors, work is fundamental to create and maintain social interaction. It is also the best tool to counter social disengagement. In addition to avoiding social disengagement, senior entrepreneurship is a tool that helps to preserve social roles. According to some interviewees, senior entrepreneurship was the most effective way to preserve their previous social role. As argued previously, senior entrepreneurs seek to provide employment opportunities to members of their communities, build relationships with other businesses' owners, and provide social services to those in need in order to help to develop the villages where they come from. In this study, we verified that similar purposes related to social entrepreneurship were also the goals of the interviewees.

Thirdly, the need for self-fulfillment. Self-fulfillment was the main motivation of some interviewees who started a business project. According to the answers to our questions, creating a business was an ambition and an old dream of some seniors.

Fourth, the need for autonomy. For an entrepreneur, autonomy means creating his or her own job and being financially and professionally independent, i.e., making one's own decisions and finding one's own solutions. According to the answers to the interviews, seniors were motivated by the possibility of attaining the autonomy entrepreneurs enjoy.

Fifth, risk-taking. Contrary to what might be expected, risk-taking does not discourage senior entrepreneurs. Although Lebanese senior entrepreneurs are aged 50 or older, an age at which many individuals worry about financial security, some interviewees claimed that they had decided to start a business project because they prefer taking risks to working as an employee. Their views corroborate the theory that risk-taking is one of the fundamental characteristics of entrepreneurs and of entrepreneurship alike.

Sixth, Job satisfaction. Some interviews showed that senior entrepreneurs resorted to entrepreneurship as a 
means to overcome the dissatisfaction with their situation at their jobs. Some interviewees reported that they felt bored, demotivated and tired while working as employees.

Seventh, the desire to leave something to their descendants. The willingness to leave an inheritance or other material benefit to their offspring was repeatedly stated in the interviews. Some of the senior entrepreneurs even decided to undertake a business project because they were determined to pass on their knowledge, expertise and heritage to future generations. We noted that the entrepreneurial intention of many Lebanese senior entrepreneurs is driven by a desire to secure a prosperous future for their future generation and their descendants. Thus, the above-mentioned group of determinants reflects the determinants of senior-entrepreneurial intent described in Ajzen's subjective norms and desirability, and previously suggested by Shapero and Sokol.

Following the results of our survey, and according to the abovementioned paradigms, we have formulated our second hypothesis:

(Hypothesis 2): Desirability factors and subjective norms, which are reflected in the desire to increase financial returns, ensure a higher level of financial security, avoid social disengagement and help to preserve one's social role. The need for self-fulfillment, the search for autonomy, the willingness to take risks, the search for job satisfaction, and a concern about inheritance significantly affect the intention of senior individuals to undertake a new business.

5.1.3 Third Group of Determinants: The Variables Related to the Perception of Control Over the Behavior and Feasibility

The variables related to the perception of control over the behavior, and perception of feasibility were identified as follows:

Some of the interviewees stated that their past experience had influenced their intention to create and start a business. Their previous experience helped them create a start-up business and contributed to their success because they had access to critical information, know-how, exclusive knowledge about their profession, and contacts with public administration officials, besides their own management experience.

For other senior entrepreneurs, having been a member of an association influenced their intention to undertake a business, since their participation in associations affected both their perceptions of feasibility and behavioral control.

Researchers have showed that assuming responsibility in a professional association helps to learn how to make rational decisions related to the business sector, manage negotiations in order to achieve the desired results, and be calm, patient, prudent and objective. Moreover, holding a relatively high position in an association teaches the individual to be a leader and promote new ideas, detect the needs of the population, and take the legal steps necessary to create a company. Thus, it is clear that having been an effective member of an association influences entrepreneurial intentions and helps senior entrepreneurs achieve their goals.

Some senior entrepreneurs interviewed in this study stated that their positive stakeholder relationships influenced their entrepreneurial intent while their social relations allowed them to invest successfully. Their success, however, may have derived from two different practices, "solitary" entrepreneurship, and entrepreneurship as a team. In addition, other responses showed that the social ties of a senior person significantly influence his or her entrepreneurial intention and, consequently, affects the feasibility of their engagement in an entrepreneurial project. A senior individual who has cultivated many social relationships is more likely to undertake a new venture than seniors who do not maintain a network of relationships because they believe they can rely on their close relations to ensure the availability of the necessary resources to manage a business.

Thus, it is clear that senior entrepreneurs who have a large social network can count on their friends' support either by making them partners, or by benefiting from their friendship in an indirect way, i.e., finding customers and receiving valuable information about suppliers or competitors.

Self-financing capacity is also a factor that determines senior entrepreneurial intention. According to some interviewees, the capacity of seniors to finance their own projects has a significant effect on their intention. We found that financial independence allows seniors to become involved in entrepreneurial activities, especially since a large number of Lebanese, particularly the elderly, avoid going into debt, a situation that contradicts Lebanese habits and values.

Availability of time was another factor that determined the entrepreneurial intentions of Lebanese seniors. Several interviewees stated that their entrepreneurial intention was affected by the fact that they had free time to undertake a new business after retirement. Based on the responses to our interviews, we noted that quite often a 
senior who has available time is more inclined to undertake a new venture, since free time allows seniors to feel that they can dedicate themselves entirely to their new entrepreneurial project.

As described above, the determinants of the third group of explanatory variables of the entrepreneurial intention among the elderly in Lebanon correspond to Ajzen's perceptions of behavioral control, and to Shapero's and Sokol's notion of feasibility of the entrepreneurial project. Thus, we formulate our third hypothesis as follows:

(Hypothesis 3): Perceptions of behavioral control, which are determined by factors such as previous work experience, affiliation to professional associations, networks of social relationships, self-financing capacity and availability of time, affect the potential perception of the feasibility a senior manager project and thereby affect his or her senior entrepreneurial intention.

\subsubsection{Fourth Group of Determinants: The Socio-Demographic Variables}

Socio-demographic variables are an important determinant of a senior entrepreneur mindset in Lebanon. These variables are mainly: family status, level of training and education, age and gender.

We noticed initially, that the marital status of a senior individual had a major impact on his or her intention to undertake a new business. Obviously, a single senior person may have the time necessary to start a venture and may enjoy a certain margin of freedom required to develop any entrepreneurial activity. However, family responsibilities with spouse and children can, in fact, push a senior individual to take the initiative to start a business.

Training and education have a double effect on the intention to launch a business. Their effect varies depending on the level of education of the agent. An untrained and uneducated senior is compelled to start a business due to subjective norms and desirability, as mentioned above. A well-trained senior, on the contrary, may be attracted to launch a venture because of his or her perceptions of behavioral control and feasibility, as previously noted.

Age has a significant effect on entrepreneurial intent. For some senior entrepreneurs, their age was the decisive factor in their decision to create a business. In their case, it was their age that influenced their willingness or desire to create a business, since many companies do not hire employees aged 50 and over. For other interviewees, older age was an advantage for potential entrepreneurs. They mentioned that they had acquired more confidence and believed that most people trust the elderly. Conversely, age is also a drawback for a potential entrepreneur due to persistent age discrimination. Thus, it is often difficult for potential senior investors to find a financial institution that is willing to finance their project.

By comparing the views of our interviewees' on age, we concluded that the importance of entrepreneurship increases with age, although, paradoxically, the barriers for potential senior entrepreneurs also increase.

Finally, gender, which is often neglected in studies about entrepreneurship in Lebanon, is an important determinant. For some interviewees, being a male is the motivating factor to become a good entrepreneur. Their view is that "men should never stay at home," they must be productive as long as they have the physical and intellectual abilities to do so. Thus, we concluded that gender has a significant effect on senior entrepreneurial intentions.

The above description of the impact of certain socio-demographic variables on the entrepreneurial intentions of seniors in Lebanon supports our fourth hypothesis:

(Hypothesis 4): Socio-demographic variables, such as family status, training and education, age and gender, significantly affect entrepreneurial intentions among seniors.

Figure 1 presents the outline of the model that is based on the analysis and theories previously described. 


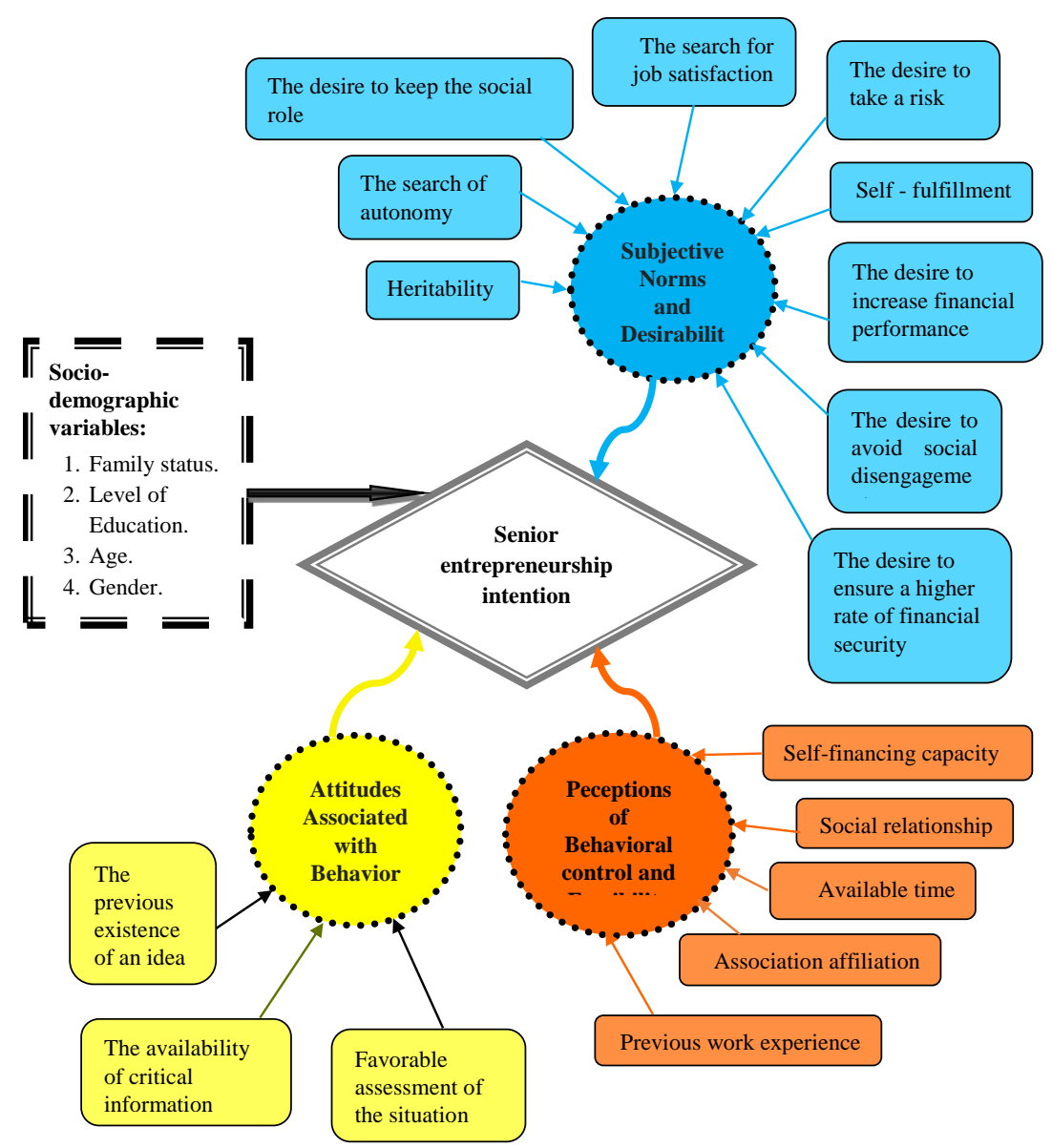

Figure 1. The conceptual model of senior-entrepreneurship intention in Lebanon

Thus, our qualitative study, allowed us to identify 21 determinants that better describe the entrepreneurial intentions among Lebanese seniors.

\subsection{Quantitative Study}

Our quantitative study is based on the answers to 1,200 questionnaires randomly distributed to seniors who work in the public and in the private sectors. In this study we addressed the answers of the 1,142 seniors who completed the questionnaire.

\subsubsection{Data Description}

This study aims to validate the conceptual model of the entrepreneurial intentions among seniors in Lebanon by drawing on the relevant theory and specific qualitative analysis to develop a final model. To do so, we used SPSS and Amos software to evaluate the data collected from the answers to a questionnaire distributed to seniors from different regions of Lebanon. The main variables explored in this study are: socio-demographic variables, entrepreneurial intention, behavioral attitudes, and factors, such as family and social environment that have an impact on entrepreneurship. Questions about the previous existence of an idea and the availability of critical information were directly asked to the respondents.

Regarding subjective norms and factors that influenced desirability, the assessment of savings and income adequacy indicated, respectively, the desire to ensure a higher level of financial security and the desire to increase returns. Satisfaction with the current work was measured in relation to the search for job satisfaction. In turn, the aversion to social isolation and the willingness to help others indicated the desire to avoid social disengagement and to preserve one's social role.

In addition, the desire for self-fulfillment was measured by addressing the dreams and ambitions of the respondent. The search for autonomy was measured through the autonomy preference. The desire to take a risk was measured in relation risk aversion, while the desire to leave an inheritance to the offsprings, was directly evaluated. The respondents directly assessed the following elements: availability of time, self-financing capacity, extensive work experience, and effective social relationships, i.e., perceptions of behavioral control. However, 
affiliation to associations was measured by asking the respondent whether he or she was a member of a municipality or an NGO.

\subsubsection{Empirical Results}

To conduct this study, we relied on structural equation models that use a confirmatory factorial study followed by another exploratory study.

Thus, we first tested the normality of the distributions by checking the values of skewness and kurtosis of the variables. According to Akrout (2010), normal distribution requires symmetry and non-flattening. Indeed, the asymmetry test is acceptable if the value of the skewness criterion is lower in absolute value than 1.96. Such a result confirms whether the observations were distributed equally around the average. The flattening test indicates the degree of concentration of the observations, which must be of less than 1.96 in absolute value. The results indicate that these tests did not violate the assumption of normality and present acceptable values. In other words, all responses were equally distributed and all variables followed the normal distribution. Hence, we did not use any transformations of variables.

We also studied the associations between the variables of the model and the socio-demographic variables. We did so to verify whether there was a relationship between the socio-demographic variables and the endogenous variables of our model. We examined whether "behavioral attitudes," "subjective norms and desirability," and "perceptions of behavioral control and feasibility" vary according to "family status," "education level," "age" and "gender." Therefore, we calculated the coefficients $t$ and $F$ to confirm the significance of the relationship between the variables.

We found that "attitudes associated with behavior" are significant in relation to gender, education and age. Thus, the respondents' age group, gender and level of education may influence their perception of the phenomenon measured, and affect their responses. As a result, we endeavored to integrate them in our model as a control variable. We also noticed that since gender has a significant effect on subjective norms and desirability it is a socio-demographic variable that must be used as a control variable. Additionally, we noted a significant relationship between the notion of "perceptions of behavioral control and feasibility" and gender. Similar results were found for the category "level of education."

To complete this study, we followed Henson and Roberts (2006) recommendation to use two independent samples, one sample for exploratory analysis and another for confirmatory analysis. Using these two samples prevents the loss of information that may occur when exploratory and confirmatory analysis is applied to the same sample. Therefore, we randomly divided our overall sample $(\mathrm{N}=1142)$ into two sub-samples. Subsequently, we randomly labeled the one used for the exploratory analysis $(\mathrm{N} 1=572)$ and the one used for the confirmatory analysis $(\mathrm{N} 2=570)$ before we proceeded to the Exploratory Factorial Analysis.

\section{a) First procedure: Exploratory Factor Analysis (EFA)}

Factor analysis is a multivariate method of data analysis that has three objectives and is generally used for metric and interval scales such as Lickert scales, which are ordinal or nominal scales. Nevertheless, according to Roussel and Wacheux (2005), in the social sciences it is accepted to treat ordinal and nominal scales as interval scales and metric variables. The three objectives of EFA are described below. According to Evrard et al. (2003), EFA reduces the number of variables. Hence, the data are summarized in a limited number of variables and are easier to analyze. Evrard et al. (2003) added that the EFA method identifies the factors from observable variables. The number of factors to be retained is determined according to empirical rules. Gerbing and Hamilton (1996) argued that factor analysis helps the researcher to retrieve the measurement model that underlies the data. Evrard et al. (2009) suggested factor analysis to test the validity of a questionnaire and to identify the dimensionality of the constructs in order to factorize the data.

Finally, confirmatory factor analysis completes the initial item purification, phase and refines the analysis performed on the new construct.

We chose to use this technique because to measure our construct we used psychometric scales, and because our variables were reflective indicators since they are seen as caused by the study's constructs.

\section{- Verification of the conditions of application of the principal axis factoring method}

According to Evrard and al. (2009), it is necessary to ensure that the collected data are factorizable, i.e., to verify if they form a sufficiently coherent whole, in order to properly look for common dimensions that are meaningful and not mere statistical artifacts. Indeed, a relevant factor analysis is an analysis whose variables are correlated.

In this research, we verified this correlation by using two tests, the Kraiser Meyer and Olkin test (KMO), and the 
Bartlett sphericity test. The Kraiser Meyer and Olkin (KMO) test analyzes the correlations between the statements and indicates whether the selected variables constitute one or more adequate measures of the concept. In our study, the value of the KMO was greater than 0.5 and allowed us to accept the factor axis (s). The Bartlett sphericity test rejected the null hypothesis of unrelated items.

\section{- Results of the exploratory phase: principal axis factoring method of the scale of SND}

The main purpose of the principal axis factoring method (PAF) is to identify the latent structure of a scale and to purify it by reducing the number of observable variables. PAF can only be performed if the number of items that make up each scale is large. In this study, factorization was inadequate for the two constructs since "behavioral attitudes" contain only three items, while "perceptions of behavioral control and feasibility" contain only five items.

After removing items with an extraction value of less than 0.4 (Costello \& Osborne, 2005, p. 4), and after using rotation Varimax, we noticed that the psychometric analysis of this scale confirmed the structure to two factors: The first factor contains four items: (a) dreams and ambitions; (b) the desire to avoid social isolation; (c) the desire or willingness to help others; and (c) the desire to leave an inheritance to descendants. Per the results, the Cronbach's alpha $=0.895$ was considered very good. The second factor contains two items: (a) the desire to take risks; (b) search for autonomy. Thus, six items concerning subjective norms and desirability were preserved.

\section{b) Second procedure: CFA and validation of the conceptual model}

After verifying the multi-normality of the constructs, we performed a confirmatory factor analysis (CFA) for subjective norms and desirability. In this analysis we examined whether it was a one-dimensional or a multidimensional concept, and verified the convergent and discriminant validity by calculating the adjustment indices and the average extracted variance. We concluded this part of the study by integrating two initial measurement models into a general measurement model, and by testing its reliability and validity. AMOS 21 software was used throughout this process.

\section{- Assurance of multinormality: preliminary to confirmatory analysis}

The multivariate normality of the variables must be tested before starting the confirmatory analysis. To test this multivariate normality, deviant or aberrant observations should be removed. Hence, we used the Amos software, which allowed us to remove observations with extreme values in order to correct the deviation from the normal distribution.

In general, the hypothesis of multivariate normality is satisfied when the Mardia coefficient does not exceed 10 (Kline, 2005), which was not the case in this study whose coefficient was 21,839 , while the Mardia ratio test (c. R.) provides a value of 26.608 for the multivariate normality hypothesis. Therefore, the null hypothesis should be rejected, since the multivariate normality was not verified. We used Amos software to remove deviant observations and removed only one observation to correct deviation from normality. In addition, we noted that the number of observations removed should not exceed $2 \%$ of the total number of observations (Kunnan, 1998, p. 299). Since the Mardia coefficient became 8,366, i.e., less than 10 (Kline, 2005) it can be deduced that the null hypothesis was accepted. Thus, we can confirm the multivariate normality for the scale of subjective norms and desirability.

\section{- Confirmatory factor analysis of the construct "subjective norms and desirability"}

Confirmatory factor analysis makes it possible to assess the quality of adjustment of the measurement model (Bagozzi et al., 1991). By adopting this method, we first compared five different models and then chose the one that could indicate the best results. We noted that the two-factor uncorrelated model and the second order model showed better results.

Subsequently, we attempted to improve the two-factor uncorrelated model and the second order model by adding covariance links between errors (Wolfle \& Ethington, 1986, p. 573). Once the two models had been upgraded, we compared their fitting qualities using the following summary table:

Table 1. Summary table of CFA results after improvement of SND models

\begin{tabular}{lcccccccccc}
\hline Designation & Chi-deux & DL & Chi deux/DL & P & NFI & TLI & CFI & GFI & AGFI & RMSEA \\
\hline 2 uncorrelated factors after purification & 2.489 & 3 & 0.8296 & 0.477 & 0.998 & 1.001 & 1 & 0.998 & 0.993 & 0.000 \\
Second-order partial measurement model & 1.54 & 3 & 0.5133 & 0.673 & 0.998 & 1.005 & 1 & 0.999 & 0.995 & 0.000 \\
The recommended values & - & - & $<2$ & - & $>0.9$ & $>0.9$ & $>0.9$ & $\geq 0.9$ & $>0.9$ & $<0.08$ \\
\hline
\end{tabular}


This table shows that the adjustment indices of the two models are quite acceptable. To decide between the two methods, we utilized the TCI index which is calculated by the following ratio: TCI = Chi-two of the first-order model / Chi-two of the second-order model

If this ratio is greater than 0.9 , it means that the second-order factor actually explains the covariance between the factors (Marsh \& Hocevar, 1985) from which the second order model must be chosen. Since in our study the calculation of this fraction yielded 1,616, we had to choose the second order model.

\section{- Confirmatory factor analysis (CFA) of the global measurement model}

After performing two partial confirmatory analyzes, we proceeded to verify the confirmatory factor analysis of the global measurement model shown in figure 2.

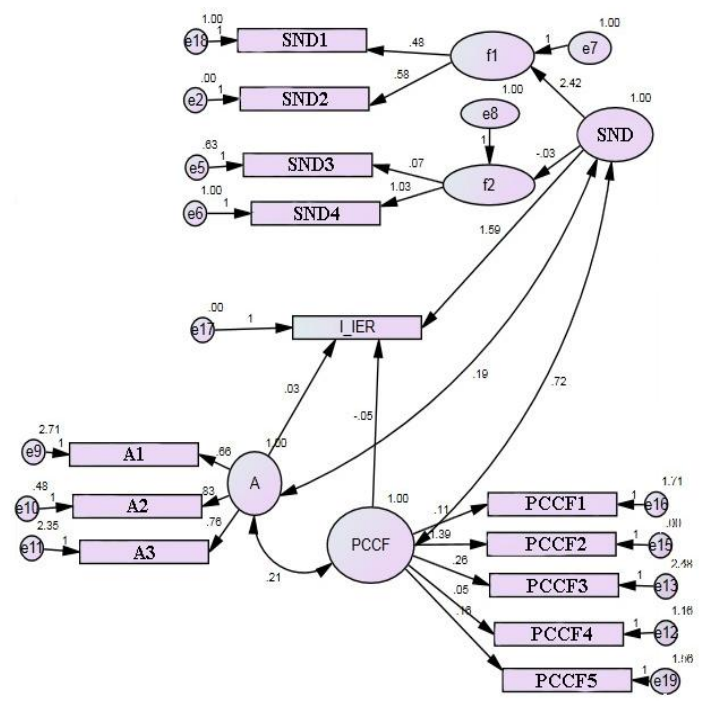

Figure 2. Initial global measurement model

Since the global measurement model was not very well adjusted to the data, we modified it by eliminating e18 and e19 and their respective variables. We thus obtained the model shown in figure 3.

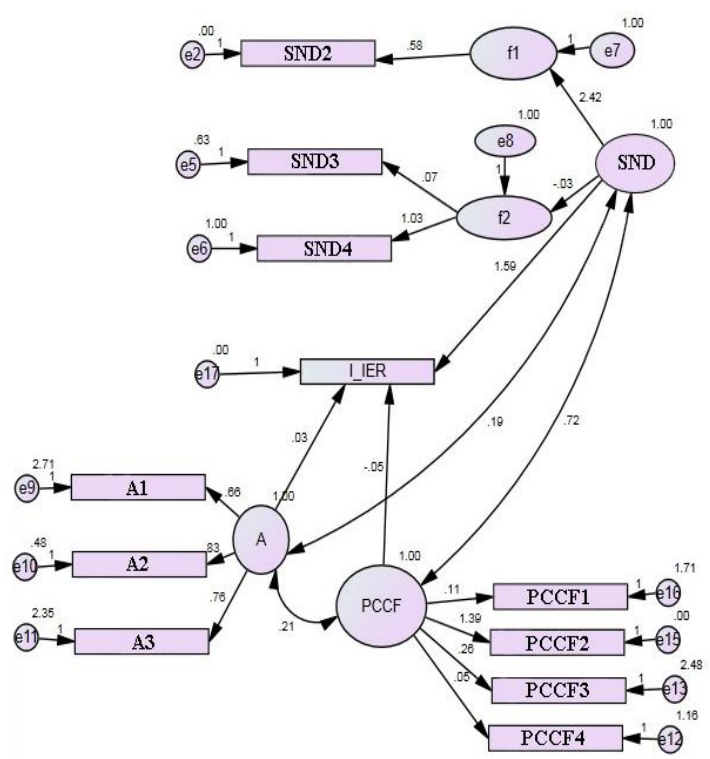

Figure 3. The global measurement model modified for the first time

The adjustment indices of the global measurement model have become suitable, so the model is well adjusted to the data.

c) Evaluation of the validity of the global measurement model

- Internal reliability or consistency test 
According to Farley and Reddy (1987, p.75), the reliability of a measure compares the true or unknown part of the information to the observed or known part. Internal reliability helps to verify whether a set of items is sufficiently homogeneous to be part of the same construct (Akrout, 2010, p. 220). To evaluate reliability, we used Average Variance Extracted (AVE) as suggested by Bagozzi and Yi (1988). To determine reliability, this measure should be greater than 0.5. According to Akrout (2010, p. 227), if the AVE is weak, it is necessary to remove the item whose factorial contribution is the weakest. VME is also used as a tool to evaluate discriminant validity.

In this study, the AVE was also used as a tool for evaluating discriminant validity. We noticed that it was also necessary to improve AVE by eliminating the item SND_2 to guarantee this reliability.

\section{- Converging validity}

For Mhiri (2013, p. 243), the extent to which the measures of the same concept by two different methods are convergent should be determined. To measure the extent of this convergence we utilized Fornell's and Laker's (1981) approach. The authors propose to use AVE as a criterion for assessing convergent validity by ensuring that it is greater than 0.5 for each construct. In this study the AVE of each construct are acceptable because they are greater than 0.5 . Thus, its convergent validity is asserted.

\section{- Discriminating validity}

According to Fornell's and Laker's test (1981), discriminating validity verifies to what extent a new construct differs from other constructs. In other words, if two constructs differ theoretically, they are empirically distinct (Akrout, 2010, p. 231). We tested the discriminant validity of our constructs by adopting Fornell's and Larcker's approach, while verifying that the AVE for each construct was greater than the square of the correlation, i.e., the structural link between the constructs.

\section{- $\quad$ Stability of the measurement model}

To check the stability of the measurement model, we used the bootstrap estimation method of replicating the fit of the model on a large number of random sub-samples derived from the main sample. We performed a $95 \%$ confidence interval estimation for 2,000 samples. The stability of the parameter should be checked when $\mathrm{P}$ is smaller at 0.05 . The results of the bootstrap on 2000 samples showed a total stability of the measurement model for the variances of the latent variables and for the SMC.

\section{- Validation of the model}

We evaluated the structural model by performing the same procedures executed to evaluate the global measurement model. Subsequently, we examined the significance of structural links, which allowed us to validate the research hypotheses.

\section{- Validation of the structural model}

According to Jolibert and Jourdan (2011, p. 467), the structural model describes the causal relationships between exogenous, i.e., explanatory latent variables, and endogenous latent variable, which are variables to be explained. Thus, the structural model constitutes "a schematization of the hypotheses of research of a scientific work" (Akrout, 2010, p. 36). Figure 4 shows the initial structure model before the control variables were integrated.

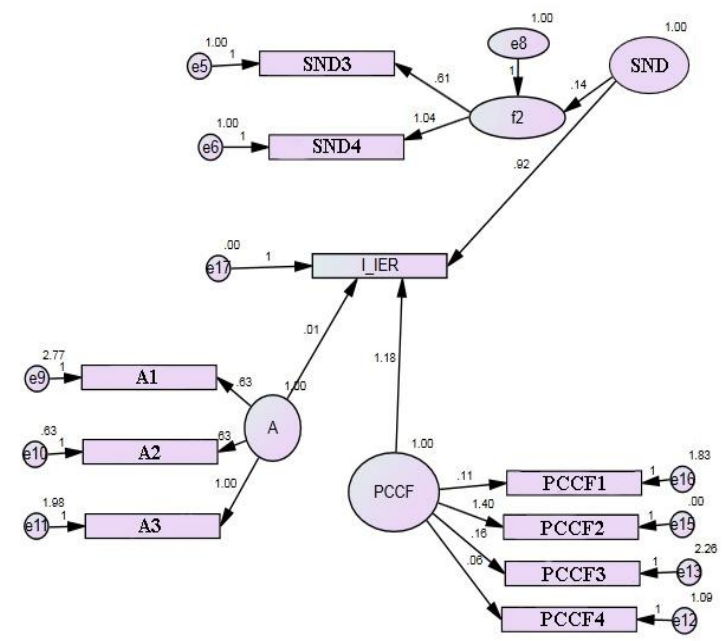

Figure 4. Initial structural model without control variables 
Subsequently, control variables must be introduced based on the study of the associations between the endogenous variables of the model and the socio-demographic variables.

Table 2. Summary table of the control variables to be introduced in the initial structure model

\begin{tabular}{ll}
\hline Construct & Control variables \\
\hline Behavioral attitudes & Gender, level of education and age. \\
Subjective norms and desirability & Gender \\
Perceptions of behavioral control and feasibility & Gender and level of education \\
\hline
\end{tabular}

Before introducing the control variables, the qualitative variables should be identified and transformed into dichotomous, i.e., binary, dummy variables. The number of these qualitative variables corresponds to the number of modalities of the qualitative variable minus 1 , which is achieved by removing the reference modality each time it is measured. Each artificial variable takes 0 or 1 as a value to distinguish two groups for each variable. In other words, the "dummy variable" allows the study of each variable at two levels of perception. In addition, the number of artificial variables created corresponds to the number of the modality of the variable minus 1 . However, it is crucial to identify which modalities should be eliminated. When the modality is an ordinal variable such as age and level of education, the central tendency is represented by the median. Thus, it should be computed by SPSS and removed (Garson, 2012). In our study, the medians for these variables were, 55 to 60 age group, respectively and the level of education "School". For nominal variables such as gender, we removed the unambiguous modality that does not have a very low number of observations (Garson, 2012). In doing so, the male category was removed. Figure 5 shows the initial structure model after the control variables were introduced.

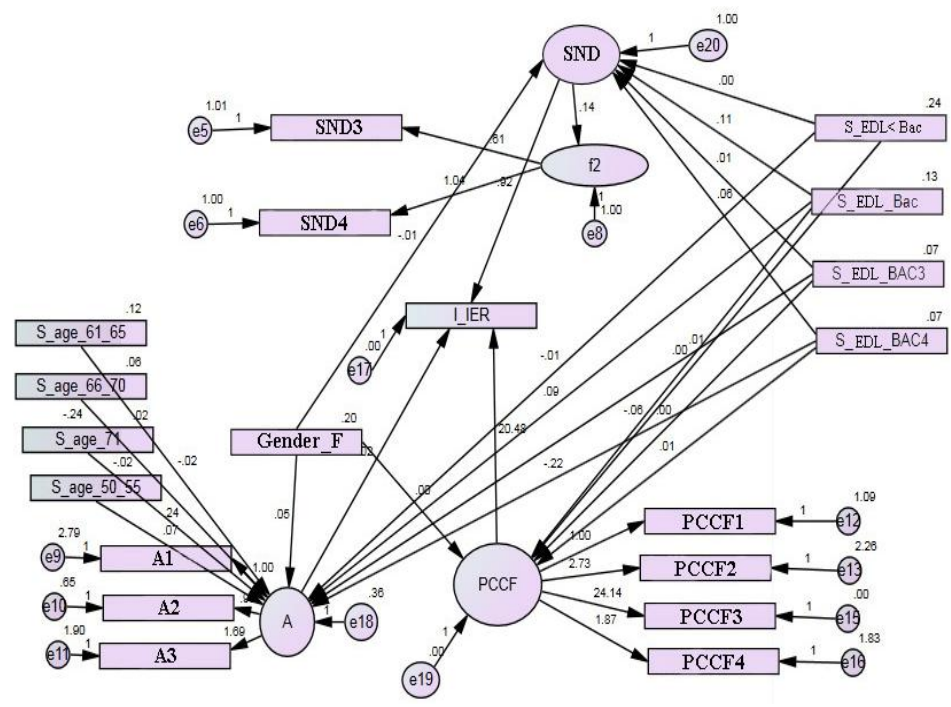

Figure 5. Initial structure model after the introduction of the control variables

In order to decide which structure model to use, we compared models with and without control variables by using the following table:

Table 3. Comparison of models without and with control variables

\begin{tabular}{lccc}
\hline Indices & Model without control variables & Model with control variables & C.R. \\
\hline Chi-deux & 189.447 & 1104.370 & 914.0923 \\
\hline DL & 35 & 142 & 107 \\
P & 0.000 & 0.000 & 0.000 \\
Chi-deux / DL & 5.412 & 7.777 & 2.365 \\
CFI (Comparative Fit Index) & 0.910 & 0.618 & 0.292 \\
TLI (indice de Tucker-Lewis) & 0.884 & 0.540 & 0.344 \\
AIC (Indice Akaike) & 229.447 & 1200.370 & 970.923 \\
CAIC (Consistent CAIC) & 350.241 & 1490.274 & 1140.033 \\
BIC (Bayesian Information Criterion) & 330.241 & 1442.274 & 1112.033 \\
\hline
\end{tabular}


It is clear that the indices of the structural model without control variables are higher than those of the structural model with control variables. Therefore, we maintained the model without the control variables for the duration of our analysis.

\section{- Stability test of the selected structural model.}

Once the structural model had been chosen, it was necessary to test its stability since P was less than 0.05 . The results of the bootstrap on 2000 samples showed a total stability of the measurement model for latent variable variances, error variances and for SMC. As regards the stability of standardized factorial contributions, stability was checked at $87 \%$ respectively. This result may reflect the fact that the questions had been misunderstood by the respondents or had confused them. Subsequently, we estimated that the model was globally stable.

\section{Validation of the Research Hypotheses}

Table 4 provides the elements that examine the validation of our hypotheses. The second column "factorial contributions" reports the estimates. The sign of each one indicates whether the relationship between the two variables is positive or negative. The P-value column indicates the significance of the relationship between these two variables. The validity of each hypothesis is tested separately.

Table 4. Effect of the independent variables on the dependent variable

\begin{tabular}{lcccc}
\hline Links & Factorial contribution & S.E. & C.R. & P-value \\
\hline I_IER<----SND & 0.924 & 0.019 & 47.692 & $* * *$ \\
I_IER<----PCCF & 1.184 & 0.037 & 32.149 & $* * *$ \\
I_IER<-----A & 0.015 & 0.036 & 0.402 & 0.688 \\
\hline
\end{tabular}

$* * *$ Significant at $1 \%$.

Hypothesis 1 postulates that attitudes associated with behavior have a significant effect on the intention of a senior to start a new business. The results show that the link between A and I_IER is not significant (CR $=0.402$ $<1.96$ and P-value $=0.688>0.05$ ). Thus, attitudes associated with behavior do not have a significant impact on the entrepreneurial intent of senior citizens in Lebanon. As a result, Hypothesis 1 was rejected and not validated.

Hypothesis 2 postulates that subjective norms and desirability factors significantly affect a senior's intention to start a business. The findings show that the SND and I_IER are positively correlated with C.R. $=47.692$ and P $<0.001$. Since the relationship between SND and I_IER is significant, we can safely state that social norms significantly determine the senior-entrepreneurial intention in Lebanon. Hypothesis 2 is thus validated.

Hypothesis 3 proposes that perceptions of behavioral control do affect seniors' intention to start a business. Static tests showed that PCCFs were positively correlated to I_ER with a CR $=32.149$ and P $<0.001$, and the relationship between PCCF and I_IER was significant. Consequently, the perceptions of behavioral control and feasibility properly explain the intention of the seniors to create a business, thus validating Hypothesis 3.

Finally, Hypothesis 4 that postulates that socio-demographic variables significantly affect the senior-entrepreneurial intention was rejected. Our quantitative study showed that all socio-demographic variables are considered control variables that do not appear in our final model and, therefore, do not have an impact on senior entrepreneurship intention in Lebanon.

Overall, we noticed that only six independents variables are relevant and have a significant impact on entrepreneurship intention among seniors in Lebanon. Moreover, the search for autonomy and the desire to take risks, which constitute subjective norms and desirability, significantly affect seniors' entrepreneurial intentions. Availability of time, self-financing capacity, affiliation to a professional association, and previous experience also have a major impact on the intention of seniors in Lebanon to pursue an entrepreneurial activity (see figure $6)$. 


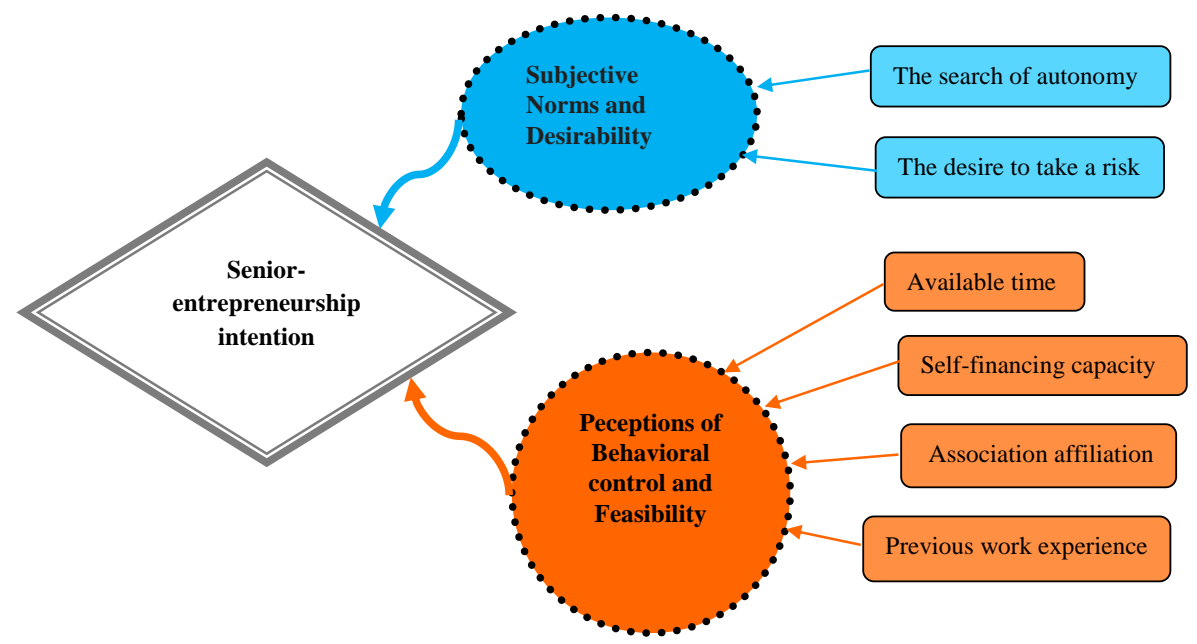

Figure 1. The final model

\section{Conclusion}

Entrepreneurship of the elderly is a field investigated by different theories, particularly because it is a relatively new and sustainable idea. In spite of their age, senior citizens are major social actors who possess great and useful experience and have a real desire to be active in their communities and to innovate.

We noticed that most seniors are motivated to create a business by "pull and push factors and, thus, are potentially affected by several policies that encourage them to initiate a venture. Conversely, they confront many obstacles, such as traditional believes and age barrier.

Based on the selected literature, we carried out a mixed study composed of qualitative and quantitative studies. The qualitative study was used to develop hypotheses that were tested in the quantitative study.

For this purpose, semi-structured interviews were performed with 50 entrepreneurs who started their business for the first time at the age of 50 or more. This helped us to preliminarily define the determinants that have a significant effect on the senior-entrepreneurial intention in Lebanon. These determinants were used to develop our model.

The determinants identified in this study were divided into three main groups: (a) behavioral attitudes, (b) subjective norms and desirability, and (c) perceptions of behavioral control and feasibility. Furthermore, we added the socio-demographic variables to the aforementioned determinant to construct a questionnaire that was distributed to 1,142 seniors. The socio-demographic variables were considered as control variables.

After we analyzed the information collected from our survey, we noticed that Lebanese seniors are motivated to start a new business mainly because they are motivated to attain a certain degree of autonomy at work and satisfy their willingness to take risks. Moreover, their projects are potentially feasible because they have available time, the necessary financial capacity, social relations cultivated during their previous affiliation with professional associations and professional experience, all of which are essential to guarantee success in their new ventures. As a result, we suggest that decision-makers focus on the above-mentioned factors that describe the entrepreneurial intention of Lebanese seniors to promote and support entrepreneurship among seniors in the country.

During our research we faced several limitations caused by the dearth of studies in the area of senior entrepreneurship, a field that only recently has gained more attention from researchers. We also recognize that this study is preliminary and lacks details.

In the process of developing our methodology, our main limitation was the contingency of our results. Below are some of the limitations we encountered in this study: the lack of studies that discuss the question of entrepreneurship of elderly in the Middle East countries, the novelty of this topic in the Lebanese context, the difficulty in finding statistics on entrepreneurship in Lebanon, the defensive attitude of the seniors interviewed when asked questions... In addition, the main managerial limitation of our work lies in the fact that we have not been able to test the final model at the international level. Testing our final model would have made it possible for us to generalize our model and promote it internationally. 
In spite of these hurdles, we feel that our study's main contribution is to offer an analysis of senior entrepreneurship in the Lebanese context, especially since during our research we did not find any previous studies about the field in Lebanon. Thus, the local model that we managed to develop has provided us with elements to further stimulate the reflection about the field of senior entrepreneurship.

It also became clear that senior-entrepreneurship is a means of serving various communities, thus giving seniors a social role, in addition to creating employment opportunities for young people. However, an interesting question still remains: what are the success factors of senior-level projects in Lebanon? Finally, our analysis of internal and external environmental factors can be the subject of further studies that reveal the impact of these determinants on the development and success of companies created by senior entrepreneurs in Lebanon.

\section{References}

Ajzen, I. (1991). The theory of planned behavior. Organizational Behavior and Human Desicion Processes, 179-211. https://doi.org/10.1016/0749-5978(91)90020-T

Akrout, F. (2010). Les méthodes des équations structurelles (1st ed.). Tunis: Imprimerie Coopi.

Bagozzi, R., \& Yi. (1991). Multitrait-multi method matrices in consumer research. Journal of Consumer Research, 17, 426-439. https://doi.org/10.1086/208568

Benredjem, R. (2009). L'intention entrepreneuriale: l'influence des facteurs liés à l'individu et au milieu. Grenoble: CERAG.

Bethlehem, J., Cobben, F., \& Schouten, B. (2009). Des indicateurs de la représentativité des réponses aux enquêtes. Symposium 2008: Collecte des données: défis, réalisations et nouvelles orientations.

Bird , B. (1988). Implementing entrepreneurial ideas: The case for intention. Academy of Management Review. https://doi.org/10.2307/258091

Bornard, F., \& Abord de Chatillon, E. (2016). Il est toujours temps d'entreprendre. Une analyse à partir de la situation de 7298 porteurs de projets. Revue Interdisciplinaire Management. https://doi.org/10.3917/rimhe.022.0044

Botham, R., \& Graves, A. (2009). The grey economy: How third age entrepreneurs are contributing to growth. London: NESTA Research report.

Boudabous, S. (2011). L'intention entrepreneuriale des jeunes diplômés. Revue libanaise de gestion et d'économie, (6). https://doi.org/10.1016/S1999-7620(11)70033-7

Bourguiba, M. (2007). De l'intention à l'action entrepreneuriale: Approche comparative auprès de TPE Françaises et tunisiennes. Université de NANCY 2, Nancy.

Costello, A., \& Osborne, J. (2005). Best practices in exploratory factor analysis: Four recommendations for getting the most from your analysis. Practical Assessment Research \& Evaluation, 10(7).

De Bruin, A., \& Firkin, P. (2001). Self-Employment and The Older Worker. Auckland: Massey University of New Zealand.

Emin, S. (2004). Les facteurs déterminant la création d'entreprise par les chercheurs publics: Application des modèles d'intention. Revue de l'Entrepreneuriat. https://doi.org/10.3917/entre.031.0002.

Evrard, Y., Pras, B., \& Roux, E. (1993). Market: études et recherche en maketing, fondements et méthodes. Paris: Nathan.

Evrard, Y., Pras, B., \& Roux, E. (2003). Market: études et recherches en marketing (2nd ed.). Paris: Dunod.

Evrard, Y., Roux, E., Desme, T., Dussaix, A. M., \& Lilien, G. (2009). Market, Fondements et méthodes des recherches en marketing (4th ed.). Paris: Dunod.

Farley, J., \& Reddy, S. (1987). A factorial Evaluation of Effects of Model Specification and Error on Parameter Estimation in a Structural Equation Model. Multivariate Behavioral Research, 22(1), 71-90. http://dx.doi.org/10.1207/s15327906mbr2201_4

Feghali, K. (2015). Les techniques et les procédures d'audit comptable et financier Principes internationaux et pratiques libanaises. Paris: L'Harmattan.

Fornell, C., \& Larcker, D. (1981). Evaluating Structural Equation Models with unobservable variables and measurement error. Journal ok Marketing Research, 39-50. https://doi.org/10.1177/002224378101800104

Garson, G. (2012). Multiple Regression. N.C: Statistical Associates Publishers. 
Gerbing, D., \& Hamilton, J. (1996). Viability of exploratory factor analysis as a precursor to confirmatory factor analysis. Structural Equation Modeling, 3, 62-72. https://doi.org/10.1080/10705519609540030

Henson, R., \& Roberts, J. (2006). Use of exploratory factor analysis in published research: Common errors and some comment on improved practice. Educational and Psychological Measurement, 66, 393-416. https://doi.org/10.1177/0013164405282485

Jolibert, A., \& Jourdan, P. (2011). Marketing research: Méthodes de recherche en marketing. Paris: Dunod.

Kautonen, T., Down, S., \& South, L. (2008). Entreprise support for older entrepreneurs: The case of PRIME in the Uk. International Journal of Entrepreneurial Behavior and Research, 85-101. https://doi.org/10.1108/13552550810863071.

Kline, R. (2005). Principles and practice of structural equation modelling (2nd ed.). New York: Guilford Press.

Krueger, N., \& Carsud, A. (1993). Entrepreneurial intentions: Apllying the theory of planned behavior. Entrepreneurship and Regional Development, 5. https://doi.org/10.1080/08985629300000020

Kunnan, A. (1998). An introduction to structural equation modelling for language assessment research. Language Testing, 15(3), 295-332. https://doi.org/10.1080/15434303.2011.582203

Maalaoui, A., Bourguiba, M., \& Safraoui, I. (2011). No country for old men and women! L'intention entrepreneuriale chez les seniors: Le cas français. Académie de l'entrepreneuriat et de l'innovation.

Marsh, H., \& Hocevar, D. (1985). The application of confirmatory factor analysis in the study self concept: First and higher order factor structures and their invariance between groups. Psychological Bulletin, 97(3), 562-582. https://doi.org/10.1037/0033-2909.97.3.562

Menvielle, L. (2011). Analyse du risque perçu chez le cyberconsommateur français et canadien, dans le processus d'achat de services: une application au tourisme médical. Thèse de doctorat en Sciences de Gestion, Institut d'administration des Entreprises de Nice.

Mhiri, S. (2013). L'impact du stress professionnel sur l'implication organisationnelle, l'absentéisme et l'intention de quitter chez les cadres. Thèse pour l'obtention du titre de docteur en sciences de gestion.

Perret, V., \& Seville, M. (2003). Fondements épistémologiques de la recherche. Paris: Dunod.

Pilkova, A., Holienka, M., \& Rehak, J. (2014). Senior entrepreneurship in the perspective of European entrepreneurial environment. Procedia Economics and Finance. https://doi.org/10.1016/S2212-5671(14)00375-X

Roussel, P., \& Wacheux, F. (2005). Management des ressources humaines: Méthodes de recherche en sciences humaines et sociales. Bruxelles: De Boeck. https://doi.org/10.3917/dbu.rouss.2005.01

Saleh, L. (2011). L'intention entrepreneuriale des étudiantes: cas du Liban. Thèse de Doctorat - Nouveau Régime Sciences de Gestion de l'Université de NANCY 2, Université de NANCY 2.

Shapero, A., \& Sokol, L. (1982). The social dimensions of entrepreneurship. Encyclopaedia of Entrepreneurship, 72-90.

Singh, G., \& De Noble, A. (2003). Early retirees as the next generation of entrepreneur. Entrepreneurship Theory and Practice, 27(3), 207-226. https://doi.org/10.1111/1540-8520.t01-1-00001

Wolfle, I., \& Ethington, C. (1986). Within-Variable. Between-Occasions Error Covariances in Models of Educational Achievement. Education and Psychological Measurement, 14, 571-583. https://doi.org/10.1177/0013164486463010

Zimmern, B., \& Kalmykova, I. (2015). Existe-t-il un lien entre création d'entreprises et croissance? Retrieved from http://www.irdeme.org/Existe-t-il-un-lien-entre-creation.html 


\section{Appendix}

List of variables used in the quantitative study

\begin{tabular}{|c|c|c|c|}
\hline $\begin{array}{l}\text { Group of latent } \\
\text { variables }\end{array}$ & Subject of the question & Symbol of the observed variable & Items \\
\hline \multirow{3}{*}{$\begin{array}{l}\text { Sociodemographic } \\
\text { variables }\end{array}$} & Age & S_age & $\begin{array}{l}50-55,56-60,61-65,66-70 \\
\text { More than } 70\end{array}$ \\
\hline & Gender & S_Gender & Male, Female \\
\hline & The level of education & S_EDL & $\begin{array}{l}\text { No level, School, High School, } \\
\text { Bachelor, PHD }\end{array}$ \\
\hline $\begin{array}{l}\text { The senior's } \\
\text { entrepreneurial } \\
\text { intention in Lebanon }\end{array}$ & The entrepreneurial intention & I_IER & $\begin{array}{l}\text { Not agree at all, Disagree, Neutral, } \\
\text { Agree, Totally agree }\end{array}$ \\
\hline \multirow{3}{*}{$\begin{array}{l}\text { Attitude toward } \\
\text { behavior }\end{array}$} & $\begin{array}{l}\text { You have an idea that can be a } \\
\text { successful investment }\end{array}$ & $\begin{array}{l}\text { A_3 (reflects the previous existence } \\
\text { of an idea) }\end{array}$ & $\begin{array}{l}\text { Not agree at all, Disagree, Neutral, } \\
\text { Agree, Totally agree }\end{array}$ \\
\hline & $\begin{array}{l}\text { You have critical information } \\
\text { regarding a likely investment topic }\end{array}$ & $\begin{array}{l}\text { A_2 (reflects the availability of } \\
\text { certain critical information) }\end{array}$ & $\begin{array}{l}\text { Not agree at all, Disagree, Neutral, } \\
\text { Agree, Totally agree }\end{array}$ \\
\hline & $\begin{array}{l}\text { You think the investment environment } \\
\text { in Lebanon is encouraging }\end{array}$ & $\begin{array}{l}\text { A_1 (explained the assessment of } \\
\text { the situation) }\end{array}$ & $\begin{array}{l}\text { Not agree at all, Disagree, Neutral, } \\
\text { Agree, Totally agree }\end{array}$ \\
\hline \multirow[t]{4}{*}{$\begin{array}{l}\text { Subjective norms and } \\
\text { desirability }\end{array}$} & You want to avoid social isolation & $\begin{array}{l}\text { SND_1 (reflects the desire to avoid } \\
\text { social disengagement }\end{array}$ & $\begin{array}{l}\text { Not agree at all, Disagree, Neutral, } \\
\text { Agree, Totally agree }\end{array}$ \\
\hline & $\begin{array}{l}\text { You want to have a social role } \\
\text { (helping the loved ones...) }\end{array}$ & $\begin{array}{l}\text { SND_2 (reflects the desire to keep } \\
\text { the social role) }\end{array}$ & $\begin{array}{l}\text { Not agree at all, Disagree, Neutral, } \\
\text { Agree, Totally agree }\end{array}$ \\
\hline & Autonomy at work attracts you & $\begin{array}{l}\text { SND_4 (reflects the search for } \\
\text { autonomy) }\end{array}$ & $\begin{array}{l}\text { Not agree at all, Disagree, Neutral, } \\
\text { Agree, Totally agree }\end{array}$ \\
\hline & You like the risky work & $\begin{array}{l}\text { SND_3 (reflects the desire to take a } \\
\text { risk) }\end{array}$ & $\begin{array}{l}\text { Not agree at all, Disagree, Neutral, } \\
\text { Agree, Totally agree }\end{array}$ \\
\hline \multirow{5}{*}{$\begin{array}{l}\text { Perception of control } \\
\text { over the behavior and } \\
\text { feasibility }\end{array}$} & $\begin{array}{l}\text { You have a great professional } \\
\text { experience in a specific field }\end{array}$ & $\begin{array}{l}\text { PCCF_4 (reflects the respondent's } \\
\text { previous work experience) }\end{array}$ & $\begin{array}{l}\text { Not agree at all, Disagree, Neutral, } \\
\text { Agree, Totally agree }\end{array}$ \\
\hline & $\begin{array}{l}\text { You are an effective member in an } \\
\text { organization }\end{array}$ & $\begin{array}{l}\text { PCCF_3 (reflects the fact of } \\
\text { affiliation to organizations) }\end{array}$ & $\begin{array}{l}\text { Not agree at all, Disagree, Neutral, } \\
\text { Agree, Totally agree }\end{array}$ \\
\hline & Your social relationships are strong & $\begin{array}{l}\text { PCCF_5 (reflects the degree of } \\
\text { social relations of the respondent) }\end{array}$ & $\begin{array}{l}\text { Not agree at all, Disagree, Neutral, } \\
\text { Agree, Totally agree }\end{array}$ \\
\hline & $\begin{array}{l}\text { You have the capacity to finance your } \\
\text { potential project }\end{array}$ & $\begin{array}{l}\text { PCCF_2 (reflects the respondent's } \\
\text { ability to finance his or her own } \\
\text { project) }\end{array}$ & $\begin{array}{l}\text { Not agree at all, Disagree, Neutral, } \\
\text { Agree, Totally agree }\end{array}$ \\
\hline & $\begin{array}{l}\text { You have available time to carry out } \\
\text { your own project }\end{array}$ & $\begin{array}{l}\text { PCCF_1 (reflects the availability of } \\
\text { the interviewee's time required for } \\
\text { entrepreneurship) }\end{array}$ & $\begin{array}{l}\text { Not agree at all, Disagree, Neutral, } \\
\text { Agree, Totally agree }\end{array}$ \\
\hline
\end{tabular}

\section{Copyrights}

Copyright for this article is retained by the author(s), with first publication rights granted to the journal.

This is an open-access article distributed under the terms and conditions of the Creative Commons Attribution license (http://creativecommons.org/licenses/by/4.0/). 